\title{
Combination Therapy Using Sodium-Glucose Co- Transporter 2 Inhibitors and Glucagon-Like Peptide-1 Receptor Agonists for Treatment of Type 2 Diabetes
}

\author{
Nasser Mikhail MD* \\ Department of Medicine, Olive View-UCLA Medical Center, David-Geffen-UCLA School of Medicine, USA
}

*Corresponding author: Nasser Mikhail MD, Chief, Endocrinology Division, Department of Medicine, Olive View-UCLA Medical Center, David-Geffen-UCLA School of Medicine, USA

\begin{abstract}
Background: The 2 drug classes of glucagon-like peptide-1 receptor agonists (GLP-1RAs) and sodium-glucose co-transporter 2 (SGLT2) inhibitors are approved for type 2 diabetes, but their concomitant use was not sufficiently studied.Aim: To assess the safety and efficacy of the combination of GLP-1RAs and SGLT2 inhibitors in type 2 diabetes.

Methods: Systematic review of English literature by search of electronic databases: Pub/MEDLINE from 2000 until July 2 , 2020. Search terms included GLP-1 receptor agonists, SGLT2 inhibitors, combination therapy, add-on therapy, type 2 diabetes, efficacy, safety. Randomized trials were included with more focus on double-blind, placebo-controlled trials. Post-hoc analysis and consensus guidelines are also reviewed.

Results: One randomized trial evaluated the co-initiation of weekly exenatide plus dapagliflozin in patients with type 2 diabetes uncontrolled on metformin. After 52 weeks, the reduction in glycated hemoglobin (HbA1c) levels with the combination therapy was less than additive being $1.75 \%, 1.36 \%$, and $1.23 \%$ with weekly exenatide + dapagliflozin, weekly exenatide + placebo and dapagliflozin + placebo, respectively. Two randomized trials evaluated the sequential addition of GLP-1 RA to ongoing SGLT2 inhibitor therapy. Both trials reported greater HbA1c reduction averaging $0.8-1.4 \%$ compared with SGLT2 inhibitor + placebo. The combination of GLP-1 RA + SGLT2 inhibitor caused significant weight loss of approximately $3.3 \mathrm{~kg}$, which was slightly less than additive, and $4.5 \mathrm{mmHg}$ reduction in systolic blood pressure (SBP), which was more than additive. In general, the adverse effects of combination therapy were expected, with no emergence of unusual adverse effects. The least tolerated combination included semaglutide due to relatively high rates of gastrointestinal adverse events and mild hypoglycemia.
\end{abstract}

Conclusions: Combination therapy of GLP-1 RA plus SGLT2 inhibitor is overall effective and safe. Further studies are needed to examine the effects of this combination on cardiovascular (CV), renal and mortality outcomes.

Keywords: Glucagon-like peptide-1 receptor agonist; SGLT-2 inhibitor; combination; efficacy; safety

\section{Introduction}

The rationale of using a combination of a GLP-1RA plus SGLT2 inhibitor relies on many factors. First, these 2 classes of drugs have different mechanisms of actions. Thus, GLP-1 RAs stimulates insulin secretion, decrease glucagon secretion, slow gastric emptying, and promotes early satiety, whereas SGLT2 inhibitors increase urinary glucose excretion [1,2]. Second, both drug classes are associated with minimal risk of hypoglycemia [1,2]. Third, and most importantly, several drugs in both classes were shown in welldesigned clinical trials to reduce CV and renal events and mortality in patients with type 2 diabetes and atherosclerotic vascular and renal diseases [3-6]. Unfortunately, data regarding the GLP-1RA/ SGLT-2 inhibitor combination is limited. The main purpose of this article is to review clinical trials that evaluate the efficacy and safety of the use of GLP-1RA plus SGLT-2 inhibitor in patients with type 2 diabetes. 


\section{Results from Randomized Double-Blind, Placebo- Controlled Trials}

There are 3 randomized trials specifically designed to examine the efficacy and safety of the combination of GLP-1 RAs and SGLT2 inhibitors [7-9]. In the DURATION-8 trial [7], the authors evaluated the simultaneous addition of drugs from both classes, whereas in the AWARD-10 [8] and SUSTAIN-9 [9] trials, the investigators used a sequential approach. Overview of these trials are presented below and summarized in (Table 1).

Table 1: Overview of randomized trials of GLP-1 receptor agonist plus SGLT2 inhibitor.

\begin{tabular}{|c|c|c|c|}
\hline Trial & Duration-8 [7] & Award-10 [8] & Sustain 9 [9] \\
\hline Design & $\begin{array}{l}\text { Double-blind, placebo-controlled, } 3 \\
\text { groups, } 52 \mathrm{wks}\end{array}$ & $\begin{array}{l}\text { Double-blind, placebo-controlled, } 3 \\
\text { groups, } 24 \mathrm{wks}\end{array}$ & $\begin{array}{c}\text { Double-blind, placebo-controlled } 2 \\
\text { groups, } 30 \text { wks }\end{array}$ \\
\hline $\begin{array}{l}\text { Patient number, age, } \% \text { of } \\
\text { women }\end{array}$ & $\mathrm{N}=695,54$ years, $52 \%$ & $\mathrm{~N}=423,57$ years, $50 \%$ & $\mathrm{~N}=302,57$ years, $42 \%$ \\
\hline $\mathrm{HbA1c}$ at baseline & $9.30 \%$ & $8.04 \%$ & $8.00 \%$ \\
\hline $\begin{array}{l}\text { Background diabetes } \\
\text { therapy }\end{array}$ & Metformin (100\%) & $\begin{array}{c}\text { Metformin }(95 \%)+* \text { SGLT2 inhibitor } \\
(100 \%)\end{array}$ & $\begin{array}{l}\text { Metformin (71\%), sulfonylurea } \\
(13 \%)+\text { SGLT2 inhibitor }(100 \%)\end{array}$ \\
\hline Intervention & $\begin{array}{c}\text { Exenatide } 2 \text { mg sc /wk + dapagliflozin } \\
10 \mathrm{mg} / \mathrm{d} \text {, exenatide + oral placebo, } \\
\text { dapagliflozin + injected placebo. }\end{array}$ & $\begin{array}{l}\text { Dulaglutide } 1.5 \mathrm{mg} \mathrm{sc} / \mathrm{wk} \text {, dulaglutide } \\
0.75 \mathrm{mg} / \mathrm{wk} \text {, placebo. }\end{array}$ & Semaglutide $1 \mathrm{mg}$ sc/wk vs placebo \\
\hline Change in $\mathrm{HbA} 1 \mathrm{c}$ & $\begin{array}{c}-1.75 \% \text { with Exenatide }+ \text { dapagliflozin, } \\
-1.38 \% \text { with exenatide, }-1.23 \% \text { with } \\
\text { dapagliflozin. P significant between } \\
\text { Exenatide + dapagliflozin vs exenatide } \\
\text { or vs dapagliflozin }\end{array}$ & $\begin{array}{c}-1.34 \% \text { with dulaglutide } 1.5 \mathrm{mg},-1.21 \% \\
\text { with dulaglutide } 0.75 \mathrm{mg} \text {, and }-0.54 \% \\
\text { with placebo. P significant between } \\
\text { dulaglutide } 1.5 \mathrm{mg} \text { and } 0.75 \mathrm{mg} \text { vs } \\
\text { placebo }\end{array}$ & $\begin{array}{l}-1.5 \% \text { with semaglutide vs }-0.1 \% \\
\text { with placebo }(\mathrm{P}<0.0001)\end{array}$ \\
\hline $\begin{array}{c}\text { Proportions of patients with } \\
\text { HbA1c }<6.5 \% \text { at the end of } \\
\text { study }\end{array}$ & $\begin{array}{l}26.3 \% \text { with exenatide + dapagliflozin, } \\
17.2 \% \text {, exenatide + placebo, and } 8.7 \%, \\
\text { with dapagliflozin + placebo }\end{array}$ & $\begin{array}{c}50 \% \text { with dulaglutide } 1.5 \mathrm{mg}, 38 \% \\
\text { with dulaglutide } 0.75 \mathrm{mg} \text { and } 14 \% \text { with } \\
\text { placebo }\end{array}$ & $\begin{array}{l}56 \% \text { with semaglutide and } 4 \% \text { with } \\
\text { placebo }\end{array}$ \\
\hline Change in weight (kg) & $\begin{array}{l}\text {-3.31 with exenatide + dapagliflozin, } \\
-1.51 \text { with exenatide, }-2.28 \text { with } \\
\text { dapagliflozin. P significant between } \\
\text { exenatide + dapagliflozin vs exenatide, } \\
\text { but nonsignificant vs dapagliflozin }\end{array}$ & $\begin{array}{c}-3.1 \text { with dulaglutide } 1.5 \mathrm{mg},-2.6 \text { with } \\
\text { dulaglutide } 0.75 \mathrm{mg},-2.1 \text { with placebo. } \\
\text { P significant between dulaglutide } 1.5 \\
\text { mg vs placebo }\end{array}$ & $\begin{array}{l}-4.7 \mathrm{~kg} \text { with semaglutide vs }-0.9 \\
\text { with placebo }(\mathrm{P}<0.0001)\end{array}$ \\
\hline $\begin{array}{l}\text { Change in systolic blood } \\
\text { pressure }(\mathrm{mmHg})\end{array}$ & $\begin{array}{l}-4.5 \text { with exenatide + dapagliflozin, }-0.7 \\
\text { with exenatide, }-2.7 \text { with dapagliflozin. } \\
\text { P significant between exenatide } \\
\text { + dapagliflozin vs exenatide, but } \\
\text { nonsignificant vs dapagliflozin }\end{array}$ & $\begin{array}{c}-4.5 \text { with dulaglutide } 1.5 \mathrm{mg},-3.2 \text { with } \\
\text { dulaglutide } 0.75 \mathrm{mg},-1.4 \text { with placebo. } \\
\text { P significant between dulaglutide } 1.5 \\
\text { mg vs placebo }\end{array}$ & $\begin{array}{l}-4.7 \text { with semaglutide vs }+1.6 \text { with } \\
\text { placebo }(P<0.0001)\end{array}$ \\
\hline Hypoglycemia & $\begin{array}{l}\text { **Minor hypoglycemia } 1.3 \% \text { with } \\
\text { exenatide + dapagliflozin, } 0.4 \% \text { with } \\
\text { dapagliflozin, } 0 \% \text { with exenatide }\end{array}$ & $\begin{array}{c}\text { Blood glucose }<70 \mathrm{mg} / \mathrm{dl} \text { in } 4 \% \text { with } \\
\text { dulaglutide } 1.5 \mathrm{mg} \text {, } 4 \% \text { with dulaglutide } \\
0.75 \mathrm{mg} \text {, and } 3 \% \text { with placebo. }\end{array}$ & $\begin{array}{l}11.3 \% \text { with semaglutide vs } 2.0 \% \\
\text { with placebo. Severe hypoglycemia: } \\
2.7 \% \text { with semaglutide, 0\% with } \\
\text { placebo (P value not reported) }\end{array}$ \\
\hline $\begin{array}{l}\text { Gastrointestinal adverse } \\
\text { effects }\end{array}$ & $\begin{array}{l}17.7 \% \text { with exenatide }+ \text { dapagliflozin, } \\
19.6 \% \text { with exenatide }+ \text { placebo, and } \\
14.2 \% \text { with dapagliflozin + placebo. }\end{array}$ & $\begin{array}{c}32.0 \% \text { with dulaglutide } 1.5 \mathrm{mg}, 21.0 \% \\
\text { with dulaglutide } 0.75 \mathrm{mg} \text {, and } 17.0 \% \\
\text { with placebo }\end{array}$ & $\begin{array}{c}37.2 \% \text { in semaglutide group and } \\
13.2 \% \text { in placebo group }\end{array}$ \\
\hline Genital infections & $\begin{array}{l}4.8 \% \text { with exenatide }+ \text { dapagliflozin, } \\
1.7 \% \text { with exenatide }+ \text { placebo, and } \\
5.2 \% \text { with dapagliflozin }+ \text { placebo }\end{array}$ & Not reported & Not reported \\
\hline $\begin{array}{l}\text { Withdrawal due to adverse } \\
\text { effects }\end{array}$ & $\begin{array}{l}4.3 \% \text { with exenatide + dapagliflozin, } \\
5.2 \% \text { with exenatide + placebo, } 3.4 \% \\
\text { with dapagliflozin + placebo }\end{array}$ & $\begin{array}{c}3 \% \text { with dulaglutide } 1.5 \mathrm{mg}, 0 \% \text { with } \\
\text { dulaglutide } 0.75 \mathrm{mg} \text {, and } 0 \% \text { with } \\
\text { placebo }\end{array}$ & $\begin{array}{c}8.7 \% \text { with semaglutide vs } 2.0 \% \\
\text { with placebo (P value not reported). }\end{array}$ \\
\hline
\end{tabular}

Data are means.

* Most common SGLT2 inhibitors are empagliflozin $10 \mathrm{mg} / \mathrm{d}$, and dapagliflozin $10 \mathrm{mg} / \mathrm{d}$.

** Minor hypoglycemia defined as blood glucose $<54 \mathrm{mg} / \mathrm{dl}$, and no loss of consciousness.

Simultaneous Addition of GLP-1 RAs and SGLT2 Inhibitors

In the DURATION-8 trial, Jabbour and colleagues randomized patients with type 2 diabetes uncontrolled on metformin (mean baseline $\mathrm{HbA1c} 9.3 \%$ ) to 3 drug regimens: weekly exenatide $2 \mathrm{mg}$ subcutaneously plus once daily dapagliflozin $10 \mathrm{mg}$, exenatide + oral placebo, and dapagliflozin plus injected placebo [7]. After 52 weeks, mean reductions in HbA1c levels were $-1.75 \%,-1.38 \%$, and $-1.23 \%$, respectively [7]. Although the reduction in HbA1c values was statistically significant in the combination group compared 
with the other 2 groups, the decrease in $\mathrm{HbA1c}$ values was clearly less than additive.

\section{Sequential Addition of GLP-1 RAs to Ongoing SGLT2 Inhibitors}

In the AWARD-10 trial, Ludvik et al evaluated the GLP-1 RA, dulaglutide, in 2 doses $1.5 \mathrm{mg}$ sc once weekly and $0.75 \mathrm{mg} \mathrm{sc}$ once weekly versus placebo as add-on therapy to ongoing SGLT2 inhibitors [8]. After 24 weeks, the reductions in mean $\mathrm{HbA1c}$ levels were $1.34 \%, 1.21 \%$, and $0.54 \%$ in patients randomized to dulaglutide $1.5 \mathrm{mg}, 0.75 \mathrm{mg}$, and placebo, respectively: $(\mathrm{P}<0.0001$ for both dulaglutide groups vs placebo) [8].

In the SUSTAIN 9 trial, Zinman, et al. evaluated another GLP-1 receptor agonist, semaglutide $1.0 \mathrm{mg}$ sc once weekly, vs placebo [9]. After 30 weeks, the decreases in mean $\mathrm{HbA1}$ c values were $1.5 \%$ and $0.1 \%$ in the semaglutide and placebo group, respectively; $\mathrm{P}<0.0001$ vs placebo [9].

\section{Sequential Addition of SGLT2 Inhibitors to Ongoing Therapy With GLP-1 RAs}

Limited data from Japanese non-placebo, controlled studies examined the addition of the SGLT2 inhibitors: empagliflozin, canagliflozin and luseogliflozin to ongoing therapy with GLP-1 RA liraglutide $0.9 \mathrm{mg} \mathrm{sc}$ day, the maximum approved dose in Japan [10-12]. These 3 studies showed further reduction in mean HbA1c levels (approximately 0.7\%), weight (2.7-3.3 kg), and SBP (7.9-8.4 $\mathrm{mmHg} 52$ weeks after the addition of SGLT2 inhibitors [10-12]. The previous combination therapy was well tolerated with no safety concerns [10-12].

\section{Effect on Weight}

The GLP-1 RA/SGLT2 inhibitor combination, whether given simultaneously or sequentially, is associated with weight loss. The magnitude of weight loss is slightly less than additive [8]. The latter finding is expected since mechanisms of weight loss are different between the 2 drug classes. Thus, GLP-1 agonists delay gastric emptying and promote early satiety, whereas weight reduction with use of SGLT2 inhibitors is mainly attributed to caloric loss secondary to glycosuria [1,2]. Using bioelectrical impedance analysis, Seino at al [12] investigated patterns of weight loss in 21 Japanese patients with type 2 diabetes 52 weeks after addition of the SGLT2 inhibitor luseogliflozin to ongoing liraglutide treatment. They found that weight loss was mostly due to loss of fat mass ( $2.49 \mathrm{~kg}$ ), whereas reduction in lean mass was minimal $(0.44 \mathrm{~kg})$ [12]. Likewise, in a small group of Swedish 25 obese subjects (mean weight $106.4 \mathrm{~kg}$ ) without diabetes, Lundkvist et al [13] reported a mean weight loss of $5.7 \mathrm{~kg}$ after 52 weeks of administration of dapagliflozin $10 \mathrm{mg} / \mathrm{d}$ + weekly exenatide $2 \mathrm{mg}$ sc. By using magnetic resonant imaging, they found that most of this weight loss was due to loss of adipose tissue (5.31 L), and to a lesser extent lean tissue (1.36 L) [13].

\section{Effect on Blood Pressure}

The addition of GLP-1 RA to SGLT2 inhibitors in simultaneous or sequential manner consistently exerts further reduction in SBP [7-12]. Unlike reduction in HbA1c levels, this reduction in SBP was more than additive [7]. On the other hand, no significant difference in diastolic blood pressure was reported in most trials between monotherapy and combination therapy [7-9].

\section{Effects on Other Intermediate Outcomes}

Changes in lipid panel are minor with combination therapy compared with monotherapy. Combination therapy is associated with mild reduction in plasma triglycerides levels (10-12\% lower than monotherapy) [6,9]. In SUSTAIN-9 trial, levels of low-density lipoprotein cholesterol (LDL-C) are 10\% lower in the combination group formed of semaglutide + SGLT2 inhibitor than in the group receiving SGLT2 inhibitor monotherapy, but no inter-group changes were reported with respect to high-density lipoprotein cholesterol (HDL-C) [9].

Post-hoc analysis of the DURATION-8 study showed that the combination of exenatide once weekly plus dapagliflozin showed stronger effects on markers of liver steatosis and fibrosis compared with each drug alone after 28 weeks of treatment [14].

SGLT2 inhibitors are known to enhance ketosis and increase serum ketones leading uncommonly to development of diabetic ketoacidosis. Interestingly, the addition of exenatide once weekly to dapagliflozin abolished the dapagliflozin-induced rise in serum ketones. Meanwhile, the addition of exenatide maintained beneficial effects of dapagliflozin such as glycosuria and increase hematocrit after 52 weeks of treatment [15].

\section{Effects on CV outcomes and mortality}

Clinical trials designed to evaluate the effects of the combination of GLP-1 RAs and SGLT2 inhibitors on CV, renal and mortality outcomes are lacking. However, the available limited data suggest that this combination might reduce CV events. Thus, in the DURATION-8 trial, adjudicated CV events were reported in $1(0.4 \%), 3(1.3 \%)$, and 3 patients $(1.3 \%)$ randomized to exenatide + dapagliflozin, exenatide + placebo, and dapagliflozin + placebo, respectively after 52 weeks [7]. In addition, post hoc subgroup analysis of the EXSCEL, a large CV trial, showed nominally significant reduction in risk of all-cause mortality among patients who received combination of weekly exenatide plus a SGLT2 inhibitor as compared with placebo (hazard ratio $0.38,95 \% \mathrm{CI}$ 0.16-0.90), or with weekly exenatide alone (hazard ratio 0.41 , 95\% CI 0.17-0.95) [16]. Rates of CV death showed similar direction [16]. Moreover, the previous drug combination was more effective than placebo or weekly exenatide alone in slowing progression of diabetic nephropathy as reflected by the improvement in slope of estimated glomerular filtration rate (eGFR) [16]. Although these 
preliminary results are encouraging, they have to be confirmed by dedicated randomized trials.

\section{Safety of the Combination of GLP-1 RA Plus SGLT2 Inhibitor}

The combination of SGLT2 inhibitors and GLP-1 RAs are generally well-tolerated, with no evidence of emergence of unexpected adverse effects or safety signals. The least tolerated combination includes semaglutide, as reflected by the relatively high discontinuation rates due to adverse effects (Table 1). The most common adverse effects occurring after the addition of GLP-1 RAs to SGLT2 inhibitors are gastrointestinal, mainly nausea and diarrhea, generally described as mild to moderate in intensity (Table 1). However, $6.7 \%$ of semaglutide-treated patients discontinued treatment prematurely due to gastrointestinal adverse effects compared to none in the placebo group [9]. Incidence of hypoglycemia was minimally increased with addition of exenatide or dulaglutide to SGLT2 inhibitors (Table 1) [7,8]. Yet, risk of hypoglycemia was substantially increased with the addition of semaglutide to SGLT2 inhibitors [9]. In fact, 17 patients (11.3\%) randomized to semaglutide reported hypoglycemia compared with 3 patients (2.0\%) receiving placebo [9]. Severe or blood glucoseconfirmed hypoglycemia $<55.8 \mathrm{mg} / \mathrm{dl}$ occurred in 4 patients $(2.7 \%)$ in the semaglutide group and in none in the placebo group [9]. Diabetic ketoacidosis, an uncommon adverse effect of SGLT2 inhibitors, was not reported so far with the use of the agents with GLP-1 RAs.

\section{Conclusion}

The combination of GLP-1 RA/SGLT2 inhibitor represents a promising approach for treatment of type 2 diabetes. However, this approach is not without limitations (Table 2). The concomitant use of this combination provides significant reduction in HbA1c levels, body weight and SBP beyond that achieved by monotherapy alone. Hence, the best candidate for this combination would be a patient with type 2 diabetes uncontrolled on metformin who suffers from weight gain and/or hypertension. Recently, the American Diabetes Association (ADA) and the European Association for the study of diabetes (EASD) recommended using the combination therapy of SGLT2 inhibitor + GLP-1 RA in a subgroup of patients with type 2 diabetes [17]. This subgroup consists of patients with suboptimal glycemic control on monotherapy and has established atherosclerotic CV disease, heart failure or chronic kidney disease [17]. In the meantime, both Associations admitted lack of evidence for the latter recommendation from randomized clinical trials. Such trials are urgently needed to evaluate the effects of the GLP1 RA/SGLT2 inhibitor combination on cardio-renal outcomes and mortality, to determine the optimum drug combination, and characterize patients likely to derive most of the benefit from this combination.
Table 2: Advantages and limitations of combination of GLP-1 RAs and SG LT2 inhibitors.

\begin{tabular}{|c|c|}
\hline Advantages & Limitations \\
\hline $\begin{array}{c}\text { Greater HbA1c reduction compared } \\
\text { with each class alone }\end{array}$ & $\begin{array}{c}\text { No data is available regarding } \\
\text { effects of the combination on } \\
\text { cardio-renal outcomes and } \\
\text { mortality }\end{array}$ \\
\hline $\begin{array}{c}\text { Weight loss and reduction in systolic } \\
\text { blood pressure appear to be additive } \\
\text { with combination therapy }\end{array}$ & Increased cost \\
\hline $\begin{array}{c}\text { No increase in hypoglycemia } \\
\text { risk overall, except when using } \\
\text { semaglutide [9] }\end{array}$ & Increase treatment burden \\
\hline
\end{tabular}

\section{References}

1. Mikhail N (2010) Is liraglutide a useful addition to diabetes therapy? Endocrine Practice 16(6): 1028-1037.

2. Mikhail N (2014) Place of sodium-glucose type 2 co-transporters inhibitors in treatment of type 2 diabetes. World J Diab 5(6): 854-859.

3. Marso SP, Daniels GH, Brown-Frandsen K, Kristensen P, Mann JF, et al. (2016) Liraglutide and Cardiovascular Outcomes in Type 2 Diabetes. N Engl J Med 375(4): 311-322.

4. Zinman B, Wanner C, Fichett D, Bluhmki E, Hantel S, et al. (2015) Empagliflozin, Cardiovascular Outcomes, and Mortality in Type 2 Diabetes. N Engl J Med 373(22): 2117-2128.

5. McMurray JJV, Solomon SD, Inzucchi SE, Køber L, Kosiborod MN, et al. (2019) Dapagliflozin in Patients with Heart Failure and Reduced Ejection Fraction. N Engl J Med 381(21): 1995-2008.

6. Perkovic V, Jardine MJ, Neal B, Bompoint S, Heerspink HJL, et al. (2019) Canagliflozin and Renal Outcomes in Type 2 Diabetes and Nephropathy. N Engl J Med 380(24): 2295-2306.

7. Jabbour SA, Frias JP, Hardy E, Ahmed A, Wang H, et al. (2018) Safety and efficacy of exenatide once weekly plus dapagliflozin once daily versus exenatide or dapagliflozin alone in patients with type 2 diabetes inadequately controlled with metformin monotherapy: 52 -week results of the DURATION-8 randomized controlled trial. Diabetes Care 41(10): 2136-2146.

8. Ludvik B, Frías JP, Tinahones FJ, Wainstein J, Jiang H, et al. (2018) Dulaglutide as add-on therapy to SGLT2 inhibitors in patients with inadequately controlled type 2 diabetes (AWARD-10): a 24-week, randomised, double-blind, placebo-controlled trial. Lancet Diab Endocrinol 6(5): 370-381.

9. Zinman B, Bhosekar V, Busch R, Holst I, Ludvik B, et al. (2019) Semaglutide once weekly as add-on to SGLT-2 inhibitor therapy in type 2 diabetes (SUSTAIN 9): a randomised, placebo-controlled trial. Lancet Diab Endocrinol 7(5): 356-367.

10. Yasuo erauchi, Utsumiya K, Yasui A, Seki T, Cheng G, et al. (2019) Safety and efficacy of empagliflozin as add-on therapy to GLP-1 receptor agonist (Liraglutide) in Japanese patients with type diabetes mellitus: a randomised, double-blind, parallel-group phase 4 study. Diabetes Ther 10(3): 951-963.

11. Harashima S, Inagaki N, Kondo K, Bpham NM, Otsuka M, et al. (2018) Efficacy and safety of canagliflozin as add-on therapy to a glucagon-like peptide- 1 receptor agonist in Japanese patients with type 2 diabetes mellitus: a 52-week, open-label, phase IV study. Diabetes Obes Metabol 20(7): 1770-1775.

12. Seino Y, Yabe D, Sasaki T, Fukatsu A, Imazeki H, et al. (2018) Sodiumglucose cotransporter-2 inhibitor luseogliflozin added to glucagon-like peptide 1 receptor agonist liraglutide improves glycemic control with 
body weight and fat mass reductions in Japanese patients with type 2 diabetes: A 52-week, open-label, single-arm study. J Diabetes Investig $9(2): 332-340$.

13. Lundkvist P, Pereira MJ, Katsogiannos P, Sjostrom CD, Johnson E, et al. (2017) Dapagliflozin once daily plus exenatide once weekly in obese adults without diabetes: sustained reductions in body weight, glycaemia, and blood pressure over 1 year. Diabetes Obes Metab 19(9): 1276-1288.

14. Gastaldelli A, Repetto E, Guja C, Hardy E, Han J, et al. (2020) Exenatide and dapagliflozin combination improves markers of liver steatosis and fibrosis in patients with type 2 diabetes. Diabetes Obes Metabol 22(3): 393-403.

15. Ferrannini E, Baldi S, Frias JP, Guja C, Hardy E, et al. (2020) Hormone- substrate changes with exenatide plus dapagliflozin versus each drug alone: the randomized, active-controlled DURATION-8 Study. Diabetes, Obes Metabol 22(1): 99-106.

16. Clegg LE, Penland RC, Bachina S, Boulton DW, Thuresson M, et al. (2019) Effects of exenatide and open-label SGLT2 inhibitor treatment, given in parallel or sequentially, on mortality and cardiovascular and renal outcomes in type 2 diabetes: insights from the EXSCEL trial. Cardiovasc Diabetol 18(1): 138.

17. Buse JB, Wexler DJ, Tsapas A, Rossing P, Mingrone G, et al. (2020) 2019 Update to: Management of hyperglycemia in type 2 diabetes, 2018. A consensus report by the American Diabetes Association (ADA) and the European Association for the Study of Diabetes (EASD). Diab Care 43(2): 487-493.

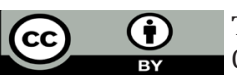

This work is licensed under Creative Commons Attribution 4.0 License

To Submit Your Article Click Here:

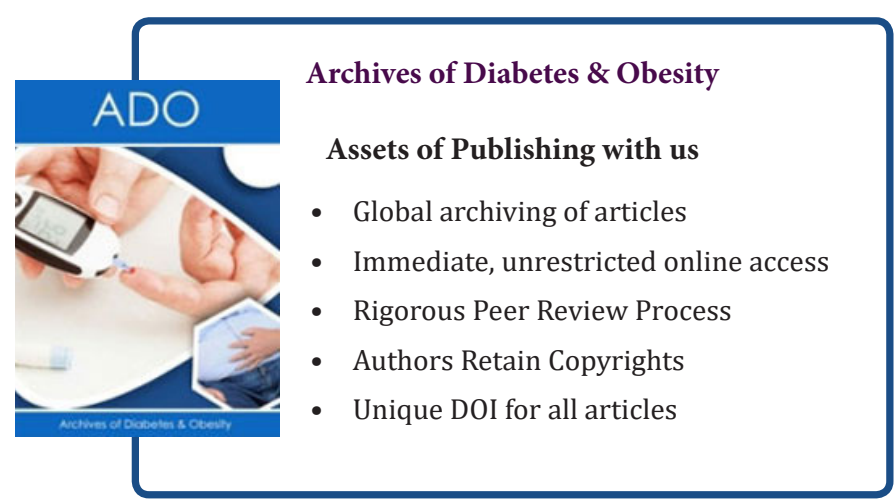

